\title{
ОСОБЕННОСТИ ПРИМЕНЕНИЯ СПЕЦИАЛЬНЫХ НАЛОГОВЫХ РЕЖИМОВ ДЛЯ САМОЗАНЯТЫХ СЕЛЬСКИХ ТЕРРИТОРИЙ
}

\author{
(C) 2019 Смирнова Ирина Викторовна \\ кандидат экономических наук \\ Марийский государственный университет, Россия, Йошкар-Ола \\ E-mail: smirnosic_ira@bk.ru
}

Исследования поддержаны грантом РФФИ 19-410-120005 p_a «Оценка перспектив развития сельских территорий Республики Марий Эл за счет развития несельскохозяйственных видов деятельноcmu»

На территории Российской Федерации теневой сектор экономики, то есть число граждан официально не трудоустроенных и не платящих налоги измеряется миллионами. Практически четверть работоспособного населения страны занято в теневом секторе экономики по данным Федеральной службы статистики. Особенно ярко это прослеживается на сельских территориях, где население традиционно, ввиду яркой сезонности сельского хозяйства и невысоких заработных плат, ищет дополнительные источники дохода. Статистика показывает, что наибольшая доля официально нетрудоустроенного населения, приходится на сельские территории. На данном показателе не могло не сказаться, то, что многие крупные предприятия (колхозы и совхозы) прекратили свое существование еще в 90-е годы, а на их смену ничего не пришло.

Изучая проблему трудоустройства на селе, невозможно обойти проблему «самозанятых граждан». А кто такие «самозанятые»? Как они отражаются в экономике? Как регистрируются и учитываются?

В соответствии с Налоговым кодексом Российской Федерации (статья 83 пункт 13) - самозанятый гражданин - это физическое лицо, которое не имеет статуса индивидуального предпринимателя, оказывает услуги другому физическому лицу для личных нужд самостоятельно, без привлечения наемных работников. Налоговые органы ставят на учет самозанятых граждан в указанном качестве по месту жительства или месту пребывания (при отсутствии у физического лица места жительства на территории Российской Федерации) на основании представляемого им в любой налоговый орган по своему выбору уведомления об осуществлении (о прекращении) деятельности по оказанию услуг физическому лицу для личных, домашних

и (или) иных подобных нужд.

По мнению Пенсионного фонда Российской федерации, самозанятые - это все, кто занимается частной практикой (ведет предпринимательскую деятельность). К самозанятым, по данной классификации, можно отнести: арбитражных управляющих, глав и членов крестьянско-фермерских хозяйств, индивидуальных предпринимателей, нотариусов, адвокатов и т.д.

Таким образом в соответствии с вышеперечисленным, самозанятым населением можно считать лиц занимающихся предпринимательской деятельность, входящей в перечень видов деятельности перечисленных в Налоговом кодексе.

Одной из важнейших проблем развития сельских территорий является формирование рыночных отношений и механизмов их регулирования в целях создания новых рабочих мест для сельских жителей и обеспечения достойного уровня их жизни.

На рисунке 1 представлена динамика изменения количества семей ведущих личное подсобное хозяйство, динамика отрицательная, что связано с тем, что сокращается сельское население.

По данным Территориального органа федеральной службы статистики по республике Марий Эл в 2016 году вели личное подсобное хозяйство 136 тысяч семей, из них более 16 тысяч для получения дополнительного дохода семьи и 4.5 тысяч - получение основного дохода, что отражено на рисунках 2 и 3.

В Республике Марий Эл из 14 административных районов наиболее перспективными для сельского туризма являются Медведевский, Килемарский, Звениговский, Юринский, Новоторьяльский, а также особенно Горномарийский и Куженерский районы. Это обусловлено их 


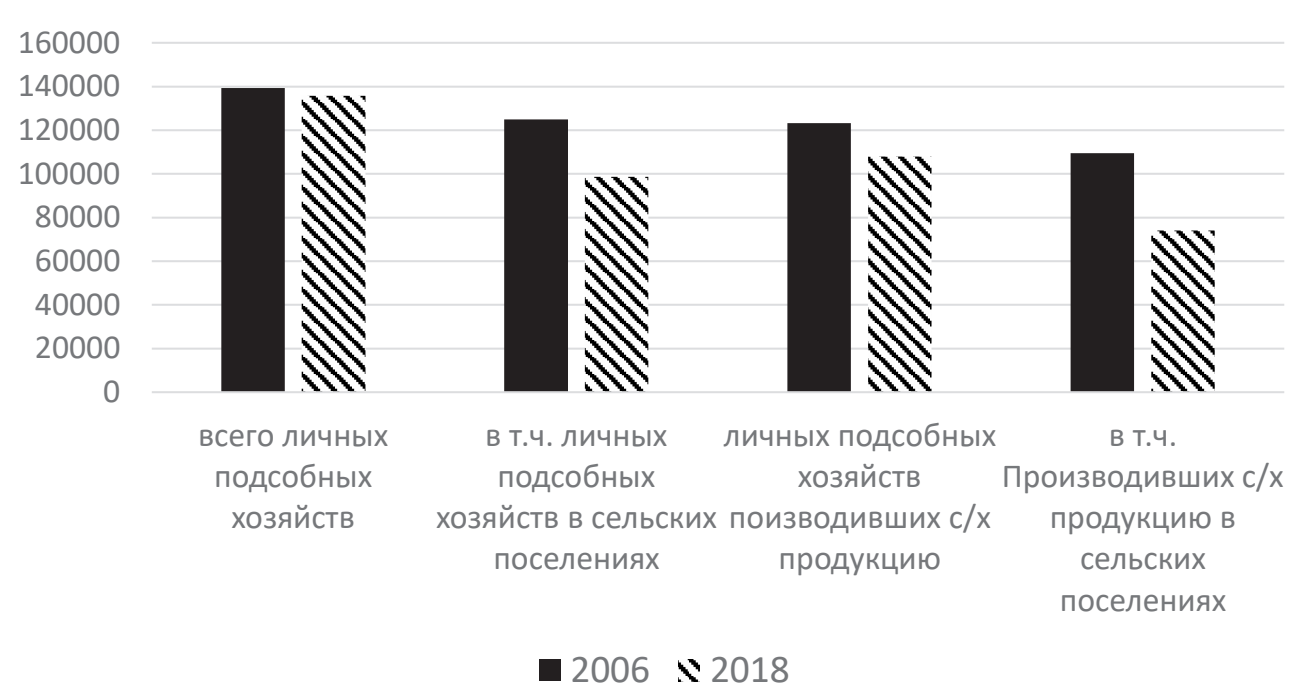

Рисунок 1. Динамика изменения количества семей ведущих личное подсобное хозяйство.

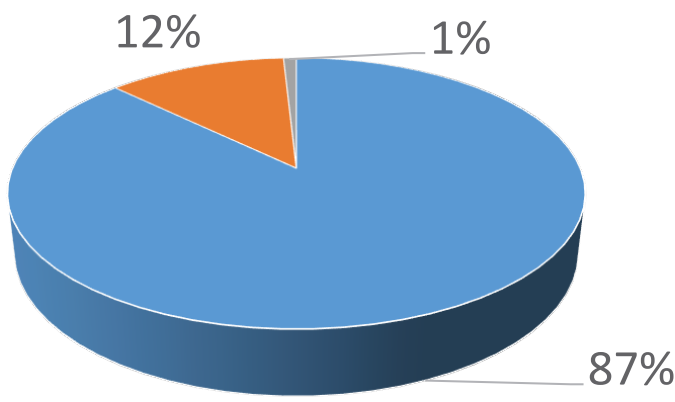

$$
\begin{aligned}
& \text { - самообеспечение продовольствием } \\
& \text { " дополнительный источник денежных средств } \\
& \text { - основной источник денежных средств }
\end{aligned}
$$

Рисунок 2. Структура использования личных подсобных хозяйств 2006 год (Данные Сельской переписи 2006 года).

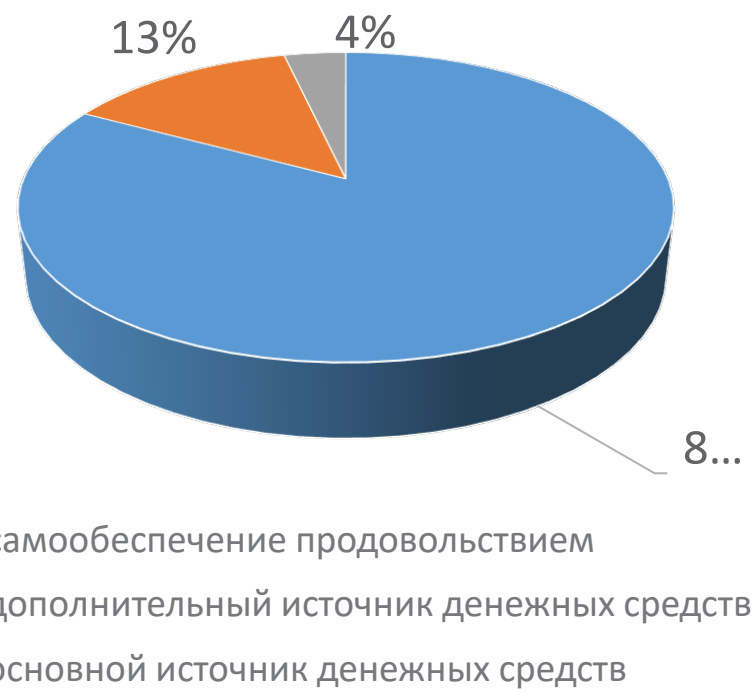

Рисунок 3. Структура использования личных подсобных хозяйств 2016 год (Данные Сельской переписи 2016 года). 
природными ресурсами. Для Горномарийского района - это близость реке Волга и уникальный для РМЭ рельеф, а в Куженерском районе - развитые системы подземных вод в виде родников и источников. В РМЭ насчитывается 20 сельских гостевых домов, которые функционируют по следующим моделям: 1) сельский гостевой дом 2) агроусадьба 3) туристский комплекс. Как объекты предпринимательской деятельности официально оформлены 14 предприятий. Остальные 6 домов сдаются в аренду на частной основе.

В последние годы в Республике Марий Эл туризм динамично развивается.

На рисунке 4 представлена динамика изменения туристского потока Республики потока по годам. Если в 200ысяч человек, в 2018-658 тысяч человек. В 2006 году в Республику Марий Эл для отдыха приезжало 145 тысяч человек, то с момента начала работы Комитета по туризму Республики Марий Эл (был организован в 2013 году) - уже 325 тысяч человек, а к 2017 туристский поток составил уже 610 тысяч человек, а в 2018 - более 658 тысяч человек.

В настоящее время одним из наиболее распространенных налоговых режимов среди лиц занимающихся предпринимательской деятельность является упрощенная система налогообложения для Индивидуальных предпринимателей, либо физические лица никак не декларируют свою деятельность. В отношении самозанятых лиц в статьи 83 и 217 Налогового кодекса Российской Федерации были внесены изменения Федеральным законом от 30.11.2016 № 401-ФЗ. Эти статьи были дополнены новыми пунктами, в которых определяются понятие, порядок постановки и уплаты налогов с доходов физических лиц в отношении самозанятых граждан.

Налог на профессиональный доход - это новый специальный налоговый режим для самозанятых граждан как для тех кто имеет статус индивидуального предпринимателя, так и тех кто его не имеет. Данный налоговый специальный режим внедрен с 1 января 2019 года. Он вводится на 10 лет на территории 4 регионов, по данным Министерства финансов Российской Федерации с 1 января 2020 года список регионов, на территории которых может применяться данная система налогообложения, может быть расширен еще на 19.

Что необходимо понимать про налог на профессиональный доход? Во-первых - это не дополнительный налог, а новый специальный налоговый режим. Во-вторых - переход на этот налоговый режим может происходить только на добровольной основе. Налогоплательщик должен зарегистрироваться, как плательщик налога на профессиональный доход в на сайте Федеральной инспекции по налогам и сборам, в приложении «Мой налог» или в других уполномоченных органах. Налогоплательщики, которые

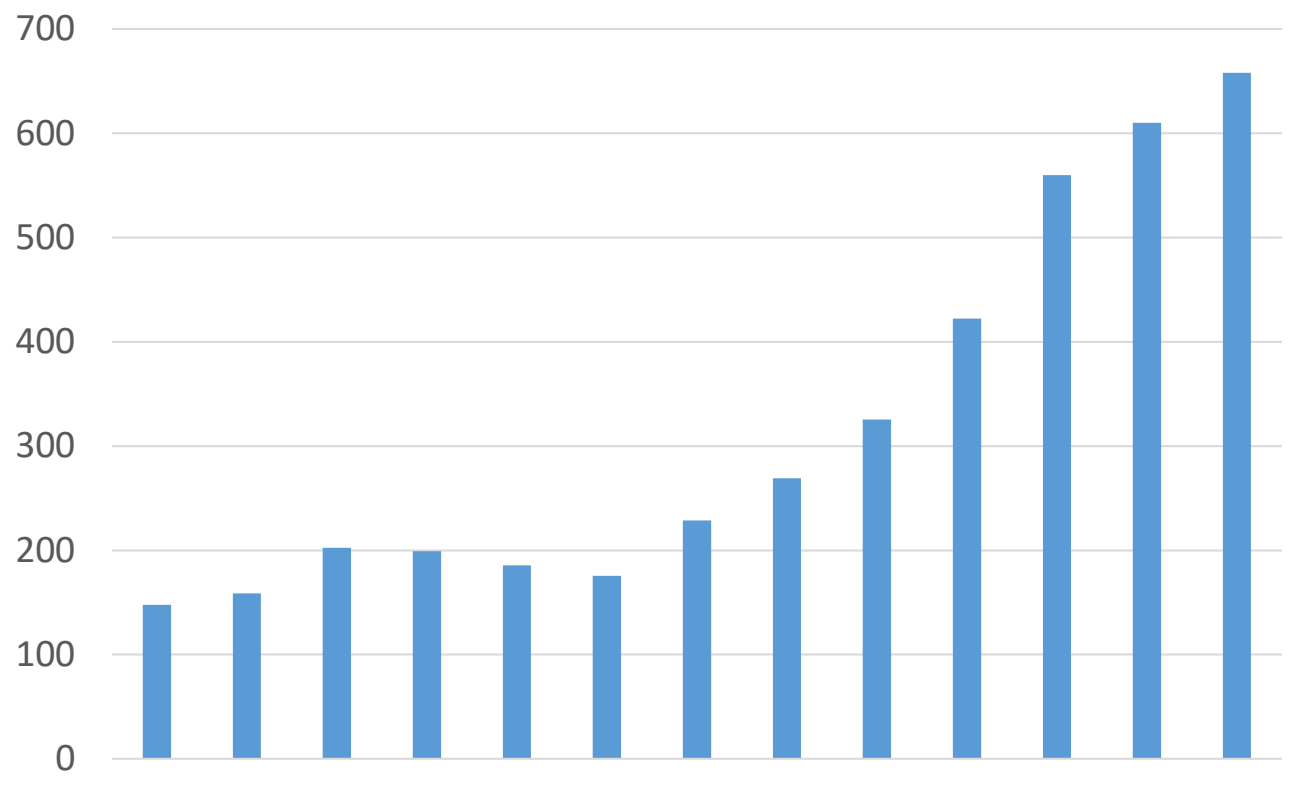

2006200720082009201020112012201320142015201620172018

Рисунок 4. Динамика изменения туристический потока Республики Марий Эл 
решат не переходить на данный специальный налоговый режим останутся на текущем режиме налогообложения. В- третьих - соответствовать требования, перечисленных в Ф3-422. А именно:

- Самозанятые получают доход от самостоятельного ведения деятельности или использования имущества.

- Деятельность ведется в регионе проведения эксперимента: Москве, Московской или Калужской областях, Республике Татарстан.

- Не имеют работодателя.

- Не привлекают наемных работников по трудовым договорам.

- Вид деятельности и условия ее осуществления не попадают в перечень исключений, указанных в статьях 4 и 6 Федерального закона от 27.11.2018 № 422-Ф3.

- Доход не превышает 2.4 миллиона рублей.

Сумма налога рассчитывается нарастающим итогом, ограничений по доходу за один месяц нет. Сумма дохода контролируется в приложении «Мой налог». Если или после того, как доход превысит указанный лимит, налогоплательщик должен будет платить налоги, предусмотренные другими системами налогообложения.

Налог на профессиональный доход предполагает использование двух видов ставок, представленных на рисунке 5 .

Налоговая ставка зависит от того, кто перечислил деньги налогоплательщику налога на профессиональный доход. Покупателя нужно указать при формировании чека в приложении «Мой налог». Учет налоговых ставок и расчет суммы налога к уплате происходит автоматически. Все произведенные начисления и предварительную сумму налога к уплате можно увидеть в приложении в любое время в течение месяца.

От каких налогов освобождает налог на профессиональную деятельность:

1. Физические лица освобождаются от налога на доходы физических лиц с тех доходов, которые облагаются данным налогом.

2. Индивидуальные предприниматели освобождаются:

а. От налога на доходы физических лиц с тех доходов, которые облагаются данным налогом;

b. От НДС, за исключением налога на добавленную стоимость при ввозе товаров на территорию России;

с. От фиксированных страховых взносов в Пенсионный фонд России.

Индивидуальные предприниматели, которые зарегистрировались в качестве налогоплательщиков налога на профессиональный доход, не уплачивают фиксированные страховые взносы вне зависимости осуществлялась или нет деятельность. При применении других специальных налоговых режимов обязательные взносы в Пенсионный фонд России уплачиваются даже при отсутствии дохода.

Еще один положительный момент данной системы налогообложения - отсутствие обязательных, минимальных или фиксированных платежей. При этом налогоплательщики налога на профессиональный доход являются участниками системы обязательного медицинского страхования и могут получать бесплатную медицинскую помощь.

Социологи Фонда общественного мнения провели опрос среди россиян и выяснили, как они относятся к законопроекту о самозанятых.

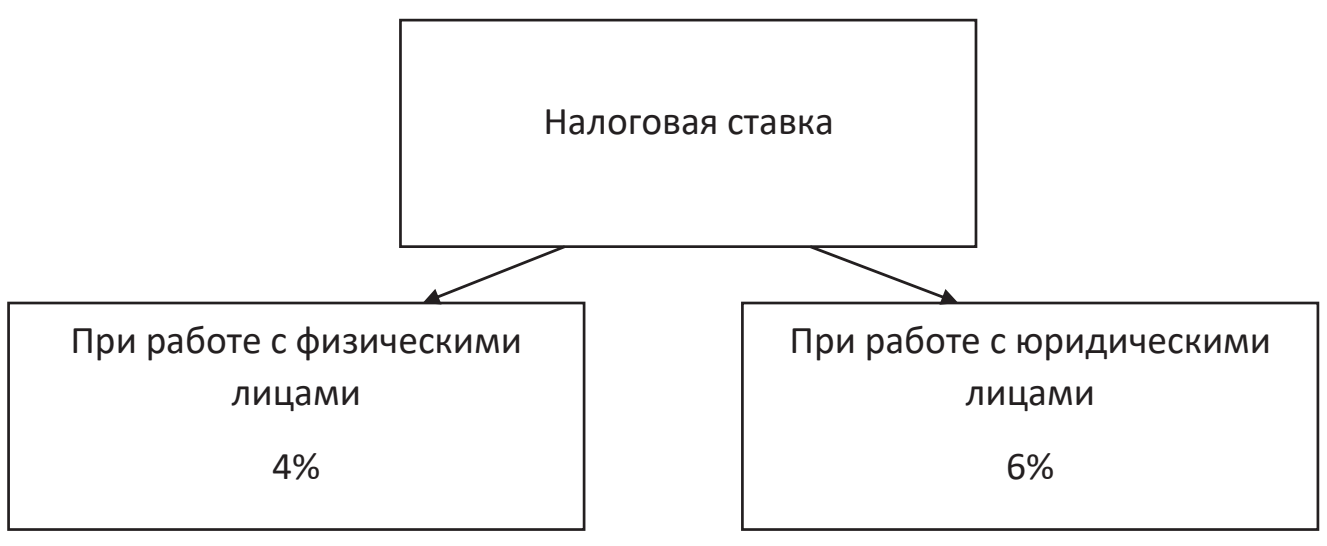

Рисунок 5. Налоговые ставки по Налогу на профессиональный доход. 


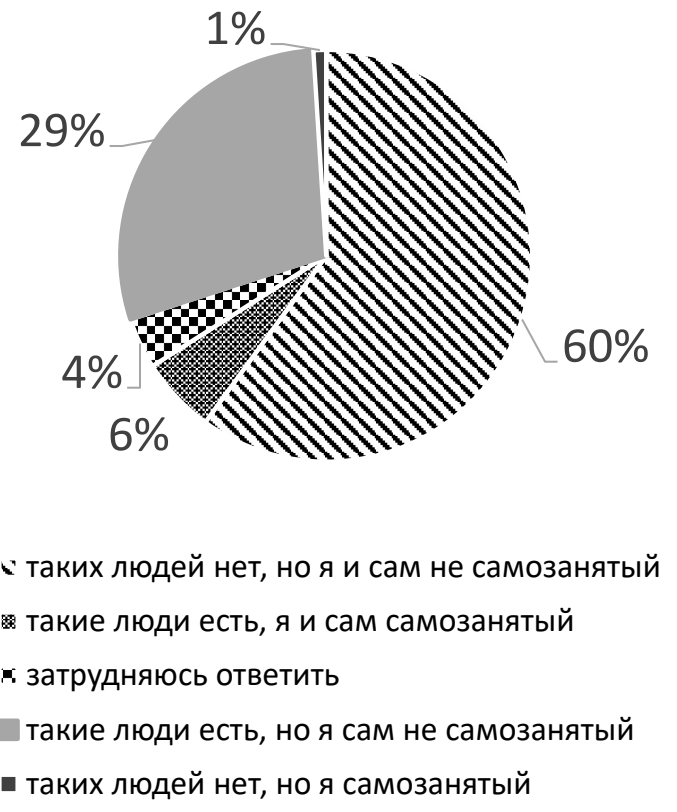

Рисунок 6. Структура ответов на вопрос «Являетесь ли Вы самозанятым, и есть ли такие люди среди Ваших знакомых»

Диаграмма, на рисунке 6, показывает ответы людей на вопрос являются ли они самозанятыми, и есть ли такие люди среди их знакомых.

Появление Федерального закона Ф3-422 обусловлено в первую очередь необходимостью создания реестра самозанятых граждан. Это связано с тем, что при распределении налоговой нагрузки данная категория граждан не участвует, что негативно сказывается на формировании бюджетов всех уровней. Однако цель введения данного налога не только и не столько пополнение бюджета, а формирование полной и достоверной базы для социального обеспечения данной категории граждан в будущем. Данная идея с налогом на профессиональную деятельность требует определенного позиционирования и разъяснений, для привлечения людей необходимо создать четкие стимулы. При многих положительных моментах отраженных в Федеральном законе Ф3-422, в нем есть и достаточное количество неточностей, а именно: во-первых: список видов деятельности самозанятых, в законе нет никакой информации связанной с несельскохозяйственными видами деятельности самозанятых сельских территорий (а развитие сельских территорий - одно из приоритетных направления развития Российской Федерации до 2035 года), во-вторых - отсутствие согласованной нормативной базы, которая бы регулировала деятельность самозанятых (могут ли самозанятые кооперироваться и выполнять работы дополняющие друг друга, отсутствие получения лицензирования на определенные виды деятельности для самозанятых).

В стране сложилась слишком масштабная теневая экономика, поэтому любые шаги к улучшению ситуации должны помочь увеличить производительность труда.

\section{Библиографический список}

1. Официальный сайт Госдумы http://sozd.duma.gov.ru/bill/551845-7

2. Официальный Интернет-портал http://www.pravo.gov.ru/

3. Электронный журнал «Главбух»

4. Информационно-правовой портал Гарант.py http://www.garant.ru/ 